\title{
BIBLIOTECA UNIVERSITÁRIA E OS INDICADORES DO SINAES: estudo do caso da Universidade de Brasília
}

\author{
Flor de María Silvestre Estela* \\ Murilo Bastos da Cunha*
}

RESUMO Este trabalho pretende obter resposta à seguinte questão: A Biblioteca Central da Universidade de Brasília (BCE/UnB) atende a todos os indicadores do Sistema Nacional de Avaliação da Educação Superior (SINAES) para o bom atendimento das necessidades de informação de seus usuários? A metodologia adotada neste trabalho foi a análise documentária a partir de fontes de informações, documentos da Universidade de Brasília (UnB) e das publicações geradas pela Comissão Própria de Avaliação, no período 20I4, para dar resposta às dimensões dos instrumentos de avaliação do SINAES, a saber: instalações físicas; instalações para o acervo e funcionamento; informatização. Tem-se por pressuposto que se essas dimensões não forem cumpridas, o público-alvo da $\mathrm{BCE} / \mathrm{UnB}$ deixará de ser usuário e se converterá em não-usuário, tendo em vista não ter conseguido satisfazer suas necessidades de informação naquela biblioteca. Os resultados dos indicadores mostram que a BCE/ UnB não está contribuindo no processo de ensino, extensão dos estudantes da UnB.

Palavras-chave: Avaliação de biblioteca. Biblioteca universitária. Sistema Nacional de Avaliação da Educação Superior. Universidade de Brasília.

\footnotetext{
* Doutoranda no Programa de PósGraduação em Ciência da Informação da Universidade de Brasília, Brasil. Mestre em Ciência da Informação pela Universidade de Brasília, Brasil. Mestre em Políticas Públicas pela Universidad Nacional Mayor de San Marcos, Peru. E-mail: silvestreestela@gmail.com.

** Doutor em Library Science pela University of Michigan, Estados Unidos. Professor permanente do Programa de Pós-graduação em Ciência da Informação da Universidade de Brasília, Brasil. Líder do Grupo de Pesquisa sobre Biblioteca Digital CNPq, Brasil.

E-mail: murilobc@unb.br.
}

\section{INTRODUÇÃO}

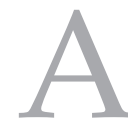

organização da informação tem como objetivo facilitar a recuperação e o uso oportuno da informação nos diversos contextos, para os quais as bibliotecas ofertam uma variedade de serviços que geram custos inerentes de operação. $\mathrm{O}$ uso desses serviços dará resposta aos serviços oferecidos pela biblioteca, há, contudo, um conjunto de membros do público alvo que não utilizam física ou virtualmente os serviços das bibliotecas. Nesse caso, esses indivíduos são identificados como "não-usuários". Os lucros de uma empresa se mede em relação à o número de clientes que compraram, então como menciona Sridhar (1994) em outras palavras, não só é tentar satisfazer e manter os clientes existentes, mas também tentar atrair os não-usuários de seus produtos. É um jogo de sobrevivência e crescimento no negócio.

Este trabalho pretende obter resposta à seguinte questão: A Biblioteca Central da Universidade de Brasília (BCE/UnB) atende a todos os indicadores do Sistema Nacional de Avaliação da Educação Superior (SINAES) para o bom atendimento das necessidades de informação de seus usuários?

Muitos podem ser os fatores pelos quais os não usuários não acessam a um serviço ou consumem um produto. Com as respostas dos objetivos pretende-se contribuir para o desenvolvimento da biblioteca universitária da UnB, brindando os recursos necessários para focar seus serviços a não-usuários, contribuindo 
para o cumprimento dos objetivos da instituição de ensino superior (IES), a saber: ensino, pesquisa e extensão.

Pelo exposto pretende-se dar resposta a nosso objetivo por meio dos resultados apresentados pela UnB-CPA ${ }^{1}$, Comissão Própria de Avaliação que foi instituída pela Lei 10.861/2004, que criou o Sistema Nacional de Avaliação da Educação Superior (SINAES), toda instituição concernente ao nível educacional em pauta, pública ou privada a constituirá. Esta comissão é responsável por coordenar os processos de avaliação interna das Instituições de Ensino Superior e pelo fornecimento de informações solicitadas pelo Instituto Nacional de Estudos e Pesquisas Educacionais Anísio Teixeira (INEP). Anualmente a CPA elabora o Relatório de Auto avaliação da instituição, com informações sobre as dez dimensões de avaliação do SINAES. Para o presente estudo considera-se o item constante do último relatório relativo à biblioteca.

\section{REVISÃO DE LITERATURA}

O estudo de usuários em bibliotecas universitárias é uma temática bastante abordada na literatura de Ciência da Informação. Já em 1984, Kremer (1984, p. 234-235) apontava que esses estudos têm sido realizados para:

conhecê-los para melhor poder servilos nas suas necessidades educacionais, didáticas e profissionais e de pesquisa, não são recentes. Há mais de 50 anos esses estudos vêm sendo realizados, tornando-se bastante frequentes depois de 1960 na Inglaterra e nos Estados Unidos.

Apresentamos uma breve revisão de literatura sobre os conceitos fundamentais da pesquisa, quais sejam, o estudo de usuários na biblioteca universitária, a BCE-UnB e o SINAES.

\section{I. Estudo de usuários na biblioteca universitária}

As bibliotecas universitárias (BU), como indica Amaral (2007), constituem um

\footnotetext{
$\bar{l}$ http://www.cpa.unb.br/
}

recurso importante para desdobramentos das capacidades que visam o atingimento dos objetivos por parte das IES. A BU visa atender as necessidades de informação de todos os usuários (estudantes de graduação, estudantes de pósgraduação, professores e pesquisadores), bem como dar suporte no processo de construção do conhecimento. Diante dessa situação nos perguntamos se a BCE/UnB realmente está cumprindo seus objetivos de atender às necessidades de todos os seus usuários.

Todos os tipos de bibliotecas têm como objetivo comum satisfazer as necessidades de informação dos seus usuários. Entretanto, de forma crescente, um percentual de usuários não utiliza física ou virtualmente os serviços das bibliotecas e, nesse caso, eles podem ser definidos como "não usuários".

Existe uma variedade de estudos sobre os usuários dos diferentes tipos de bibliotecas, contudo, conforme menciona Dumont (1994), são poucos os esforços para estudos de não usuários, apesar de ser uma realidade em todas as bibliotecas: a existência dos não usuários.

Hoje os serviços prestados pelas bibliotecas mudaram com o avanço da tecnologia e as mídias sociais que proporcionam outras formas de aprender a lidar com a informação. Uma nova geração de usuários que não utiliza os serviços tradicionais das bibliotecas estáticas as quais se limitam a um espaço físico e com serviços básicos em muito dos casos. A esse respeito, Diógenes (2012) em sua pesquisa "A futura biblioteca universitária", nos aponta a importância dos indicadores de tecnologia e dos estudos de necessidades de informações para atender às necessidades dos usuários envolvidos no processo de ensino-aprendizagem. Para a autora

\footnotetext{
Quanto ao usuário, a exigência deles para acesso cada vez mais rápido aos serviços de informação oferecidos e a necessidade de conhecer o comportamento do usuário são tendências expressivas que colocam o usuário em posição de destaque e chama a atenção de que é a ele que a biblioteca deve servir nas suas necessidades de informação de aprendizagem, ensino, pesquisa e extensão, no âmbito da universidade. (DIÓGENES, 2012, p. III).
}

Os usuários de bibliotecas universitárias (BU) são indivíduos ávidos de informação e 
que, geralmente, são autossuficientes na tomada de decisões e tornam-se, por sua vez, criadores e coprodutores de informação e conteúdo. São os usuários autónomos que estão cada vez mais familiarizados com as tecnologias, como descrevem Cunha et al. (2015). Esses autores têm uma outra forma de classificar esses usuários, isto é, de acordo com a geração a que pertencem.

\begin{abstract}
usuários da geração $Y$ : também conhecida como geração do milênio ou geração da internet. São os filhos da geração $X$, que nasceram entre 1980 e 1999. [...] Geração num contexto de crescimento das tecnologias, sistemas de comunicação, intensificação da TV como mídia. Por isso, têm mais intimidade com informática. [...] fizeram várias aulas extraclasse na infância inglês, esportes etc. (CUNHA e.t al. 2015, p.3I)
\end{abstract}

Cunha et al. (2015) também mencionam a importância de fazer um estudo de usuários nesse universo amplo e diversificado com a finalidade de entender quais são suas necessidades e como eles fazem para satisfazê-las, esses usuários são autônomos na busca e avaliação da informação; a biblioteca universitária precisa identificar a faixa etária em que se situam e ter que conhecer se ela está satisfazendo as necessidades desses usuários; caso contrário, existe o perigo de eles se transformarem em não usuários.

Existe uma variedade de estudos sobre os usuários dos diferentes tipos de bibliotecas, contudo, conforme menciona Dumont (1994), são pouco os esforços para estudar os não usuários, apesar de serem uma realidade em todas as bibliotecas.

Mas, quem é o não-usuário? Ele pertence ao público-alvo de uma determinada biblioteca que, por diversas circunstâncias, não faz uso dos serviços providos por essa biblioteca. Nesse sentido é muito importante levar em consideração todos os aspectos mencionados no primeiro contato dos universitários com a biblioteca. Este fato pode definir se eles se tornarão usuários ou não-usuários.

Quanto mais atrativo for um produto ou um objeto mais ele chamará atenção como indicam Rocha e Kafure (2014). Por outro lado, Costa (2009, p. 9) aponta que os "produtos atrativos funcionam melhor, quanto mais atrativos mais emoções positivas despertam, o que, por sua vez, afeta o processo mental tornando o indivíduo mais criativo e resistente aos problemas".

\subsection{A biblioteca central da unb e o SINAES}

Pelo exposto é muito importante conhecer como a BCE/UnB vem sendo avaliada no componente de Auto avaliação Institucional, relativo ao ano de 2014, o qual foi elaborado sob a coordenação da Comissão Própria de Avaliação (CPA/UnB) nos indicadores de infraestrutura, serviços, coleções e informatização, pelo Sistema Nacional de Avaliação da Educação Superior (SINAES). O resultado do item BU é de suma importância no contexto das bibliotecas universitárias.

Descrever o processo de avaliação interna da BCE/UnB implica refletir incialmente sobre sua trajetória de 55 anos. No contexto da criação da Universidade de Brasília - UnB em 1962, passando por muitas circunstâncias políticas, sociais e culturais que historicamente a constroem como o modelo de universidade no Brasil.

A criação da UnB representa o passo por um dos três grandes momentos que marcaram o desenvolvimento da educação superior no DF como menciona Sousa (2010), o primeiro momento vai de 1962 a 1994, corresponde à gênese e instalação das primeiras instituições uma pública e as demais de natureza privada. É esse primeiro momento que representaria a consolidação da UnB passando ela por reforma no seu plano inicial, mantendo o pensamento dos grandes intelectuais formados nas salas de aulas na época do militarismo e finalmente a UnB atende as demandas sociais de acesso na educação superior.

Agora a UnB é uma universidade moderna que promove o ensino a pesquisa e a extensão como suas finalidades essenciais descritas no seu estatuto e no regulamento geral. De acordo com o segundo item, do artigo 41, Capítulo V, Título II, do Estatuto da UnB, publicado no DOU n. 7, de 11/01/94, e atualizado em $1^{\circ} / 7 / 2011$.

A missão da BCE/UnB é muito clara: "Promover e garantir à comunidade universitária o acesso à informação científica e o compartilhamento do conhecimento científico 
no âmbito do Sistema de Bibliotecas da UnB, contemplando o ensino, a pesquisa e a extensão" (UnB. BCE, 2011). Nesse sentido queremos conhecer de que maneira a $\mathrm{BCE} / \mathrm{UnB}$ vem contribuindo para a satisfação das necessidades de informação de seus usuários-alvos, por meio dos seus serviços e infraestrutura.

A não satisfação dos usuários-alvos poderia acontecer por muitos fatores, entre eles o desconhecimento dos serviços, infraestrutura inadequada ou bibliografia desatualizada. O problema vai além ao fato de fazer um diagnóstico e conhecer as causas do não uso da biblioteca; o ponto principal é que a $\mathrm{BCE} / \mathrm{UnB}$ não estaria contribuindo no desenvolvimento do ensino, pesquisa e extensão, quando os usuários não estivessem satisfazendo as suas necessidades de informação. As necessidades insatisfeitas podem provocar o não uso dos serviços tornando-se os usuários da $\mathrm{BCE} / \mathrm{UnB}$ em não usuários de informação.

Nesse sentido, vamos conhecer como a BCE/UnB tem sido avaliada no que se refere as coleções e infraestrutura na última avaliação da UnB realizada pelo do Sistema Nacional de Avaliação da Educação Superior (SINAES). O quadro 1 mostra os componentes do Sistema.

Quadro 1 - Componentes do SENAIS e avaliação da BU

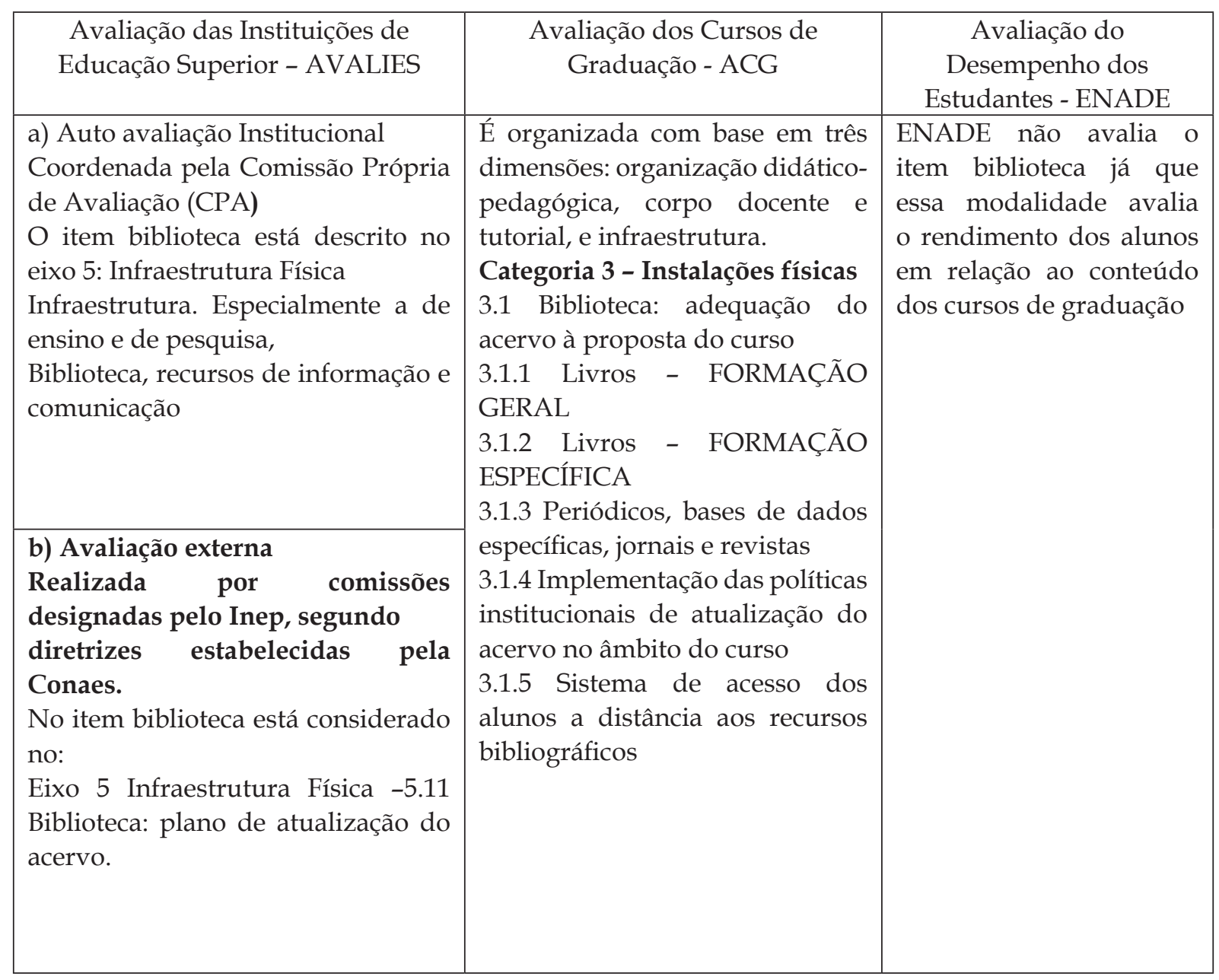

Fonte: Adaptado de (BRASIL, 2004a) 
As bibliotecas universitárias, como menciona Heloisa Brasil (2011), formam parte neste processo avaliativo, sendo consideradas como importante item para o desenvolvimento dos estudantes, e que os processos da avaliação institucional do SINAES e as condições das bibliotecas têm grande peso na pontuação do item infraestrutura institucional. Entretanto, para Holanda (2006), nessa Avaliação do MEC, como é conhecida essa política, a centralidade são as instalações físicas, e nesse sentido, há ênfase exagerada nas estruturas físicas das bibliotecas. Sendo assim, faz-se importante uma análise do item biblioteca nos componentes do SINAES².

Essa avaliação institucional possui duas etapas: a auto avaliação e a avaliação externa in loco. A auto avalição é conduzida pela sua Comissão Própria de Avaliação (CPA) com base nas diretrizes e no roteiro da Comissão Nacional de Avaliação da Educação Superior (CONAES) ${ }^{3}$. A avaliação externa ou avaliação in loco tem como referência os relatórios de auto avaliação.

\subsection{Auto avaliação}

No documento de orientações gerais para o roteiro da auto avaliação das instituições da Comissão Nacional de Avaliação da Educação Superior (BRASIL, 2004b) o item referente à avaliação das bibliotecas aparece na dimensão 4.7 (Infraestrutura física, especialmente a de ensino e de pesquisa, biblioteca, recursos de informação e comunicação). Exemplos de alguns indicadores desta dimensão são:4

- $\quad \mathrm{n}^{\circ}$ de bibliotecas (central e setoriais);

- acesso a bases de dados e bibliotecas virtuais;

- $\quad \mathrm{n}^{\mathrm{o}}$ de livros, periódicos e títulos em geral;

- $\mathrm{n}^{\mathrm{o}}$ e condições de laboratórios de informática;

As perguntas na autoavaliação se complementam para uma visão geral da biblioteca, por exemplo existem perguntas especificas sobre satisfação das necesidades de informação dos usuarios "Qual o grau de satisfação dos usuários

2 As dimensões de SINAES. http://www.planalto.gov.br/ccivil 03/ ato2004-2006/2004/lei/lI 0.86I.htm http://www.planalto.gov.br/ ccivil_03/_ato2004-2006/2004/lei/l10.86I.htm

3 http://portal.inep.gov.br/superior-avaliacao_institucional Acesso em: 6 jan. 2016.

4 https://www.puc-campinas.edu.br/midia/arquivos/20I4/jan/proavi--roteiro-autoavaliacao-orient-gerais-2004I.pdf com relação ao sistema de acesso aos materiais e a sua consulta, "Qual é a satisfação dos usuários com a quantidade, qualidade e acessibilidade da bibliografia?" (BRASIL, 2004b). As perguntas abertas que se caracterizam por apresentar o parecer dos entrevistados as quais são confrontadas com os indicadores da avaliação interna subsidiando informação para as melhoras das IES.

\subsubsection{Avaliações dos cursos da graduação - bibliotecas universitárias}

Conforme o Art. $4^{\circ}$ do SINAES a avaliação dos cursos de graduação tem por objetivo identificar as condições de ensino oferecidas aos estudantes, em especial as relativas ao perfil do corpo docente, às instalações físicas e à organização didático-pedagógica, (BRASIL, 2004a). Com relação às bibliotecas são: 3.6. Bibliografia básica, 3.7. Bibliografia complementar, 3.8. Periódicos especializados (ver quadro 2).

Quadro 2 - Indicadores do SINAE para a biblioteca

\begin{tabular}{|l|l|}
\hline \multicolumn{1}{|c|}{ Indicador } & \multicolumn{1}{|c|}{ Conceito } \\
\hline 3.6. Bibliografia básica & \\
(Para fins de autorização, & \\
considerar o acervo da & \\
bibliografia básica disponível & \\
para o primeiro ano do curso, se & \\
CST, ou dois primeiros anos, se & \\
bacharelados/licenciaturas) & Os conceitos \\
Nos cursos que possuem acervo & dos cursos \\
virtual (pelo menos 1 título & variam de 1 a 5 \\
virtual por unidade curricular), a \\
proporção de alunos por exemplar \\
físico passa a figurar da seguinte \\
maneira para os conceitos 3, 4 e 5: & \\
\hline $\begin{array}{l}\text { 3.7. Bibliografia complementar } \\
\text { (Para fins de autorização, }\end{array}$ & \\
considerar o acervo da & \\
bibliografia complementar & \\
disponível para o primeiro & \\
ano do curso, se CST, ou dois & \\
primeiros anos, se bacharelados/ & \\
licenciaturas) & \\
\hline $\begin{array}{l}\text { 3.8. Periódicos especializados } \\
\text { (Para fins de autorização, } \\
\text { considerar os periódicos relativos } \\
\text { às áreas do primeiro ano do curso, } \\
\text { se CST, ou dois primeiros anos, se } \\
\text { bacharelados/licenciaturas) }\end{array}$ & \\
\hline
\end{tabular}

Fonte: Adaptada do INEP (2015) 
O instrumento da avaliação dos cursos de graduação permite que o avaliador analise as condições da instituição conforme descrito nos relatórios emitidos pelas IES (BRASIL, 2011).

$\mathrm{O}$ desenvolvimento de coleções nas bibliotecas universitarias mudou muito com o acesso à World Wide Web (WWW); as bibliotecas tradicionais agora também podem ser digitais. Cunha (2010) enfatiza as mudanças e adaptações as bibliotecas universitárias têm que assumir como: a introdução do livro eletrônico e o surgimento de um novo acervo ligado aos dados de pesquisa científicas (e-science); o espaço físico da biblioteca; os produtos e serviços, enfatizando a referência digital, o repositório eletrônico; as inovações e tecnologias que afetam a unidade de informação e, por último, a importância da cooperação bibliotecária como elemento facilitador para a absorção dessas mudanças. A nosso ver, todos os elementos mencionados por esse autor deveriam ser considerados nos critérios de avaliações do SINAES.

\section{MATERIAIS E MÉTODOS}

A coleta de dados foi baseada na análise documentária a partir das publicações geradas pela Comissão Própria de Avaliação (CPA), no período 2014, para dar resposta às dimensões dos instrumentos de avaliação do SINAES, referente ao item biblioteca, considerando os itens de instalações físicas; serviços, acervo, funcionamento e informatização.
O Relatório de Auto avaliação Institucional da Universidade de Brasília, relativo ao ano de 2014, foi elaborado sob a coordenação da Comissão Própria de Avaliação (CPA/UnB) e baseia-se na Nota Técnica INEP/DAES/ CONAES $n^{\circ} 65$ publicada em 9 de outubro de 20143. O presente relatório considera as dez dimensões previstas na lei do SINAES.

\section{RESULTADOS}

Apresentamos, a seguir, a descrição dos indicadores do auto avaliação institucional que corresponde ao eixo 5: Infraestrutura Física, dimensão 7, da BCE- UnB.

A comunidade universitária foi consultada acerca da infraestrutura da UnB. No total, foram dezoito quesitos relacionados às instalações físicas, biblioteca, espaços para lazer e atendimento, recursos de tecnologia, entre outros, que professores, técnicos e alunos puderam avaliar e sugerir melhorias. A seguir, apresentam-se os resultados dessa etapa da auto avaliação (UnB, 2015, p. 171).

Quanto à infraestrutura da biblioteca constante do gráfico 1, 15\% dos estudantes disseram ser ruim; $22 \%$ péssimo e $28 \%$ regular; entre os docentes, $34 \%$ disseram ser regular. Entre os técnicos, as respostas, em sua maioria, se dividiram entre boa (35\%) e regular (31\%). Os dados mostram que os estudantes, docentes e técnicos percebem as instalações da BC como regular para satisfazerem suas necessidades. $O$ indicador que refere na infraestrutura ótimo tem porcentagem muito baixa.

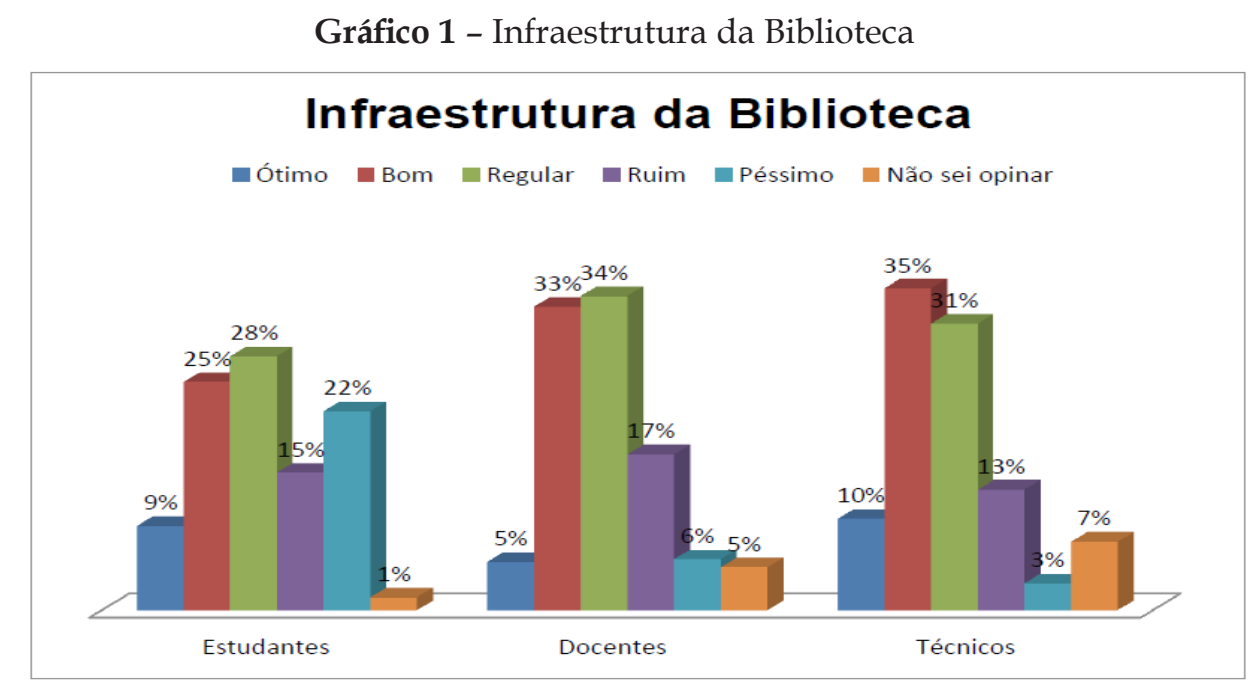

Fonte: UnB (2015, p. 175) 
A biblioteca universitária ideal se caracteriza por ser um lugar agradável, confortável, com iluminação adequada, mesas confortáveis, tomadas suficientes, ventilação adequada, como indica Cunha (2010). Ela geralmente é abrigada em belos e espaçosos prédios, com áreas para salas de leitura, para reuniões em grupo com o necessário silêncio e conforto para facilitar as tarefas ligadas ao aprendizado e a interação com o conhecimento registrado e, o mais importante, atendendo a seus usuários alvos. Segundo as respostas do gráfico 02 a BCE/UnB não está cumprindo com esses indicadores.

Outro dos indicadores do SINAES é "A quantidade de postos na biblioteca e salas de leitura que são adequadas às necessidades dos usuários? ". Os ambientes da BCE/UnB nos últimos anos foram convertidos num lugar accessível para os chamados "concurseiros" os quais ocupam os espaços destinados para os estudantes como menciona Silva (2013). Esta "invasão" pode ter sido gerada pelo grau de dificuldade dos concursos para o ingresso na área pública e à grande concorrência, os candidatos estão cada vez mais procurando formas de se preparar para tal, através de cursinhos preparatórios, cursos via web, grupos de estudos, entre outros. Como nem todos têm acesso, ou até mesmo não se encaixam em uma dessas opções citadas, preferem outros meios, grande parte desse público recorre às bibliotecas públicas ou bibliotecas universitárias, pois ali encontram um ambiente com espaço amplo e silencioso para se prepararem. A BCE/UnB, nesse caso estaria satisfazendo as necessidades dos não usuários alvos.

Em relação aos serviços oferecidos pela $\mathrm{BCE} / \mathrm{UnB}$, segundo o gráfico 2 , os usuários alvos principais - os estudantes - $24 \%$ opina que os serviços são regulares, $11 \%$ ruim, $10 \%$ péssimo e somente $38 \%$ opinam que os serviços são bons.

Gráfico 2 - Serviços oferecidos pela Biblioteca

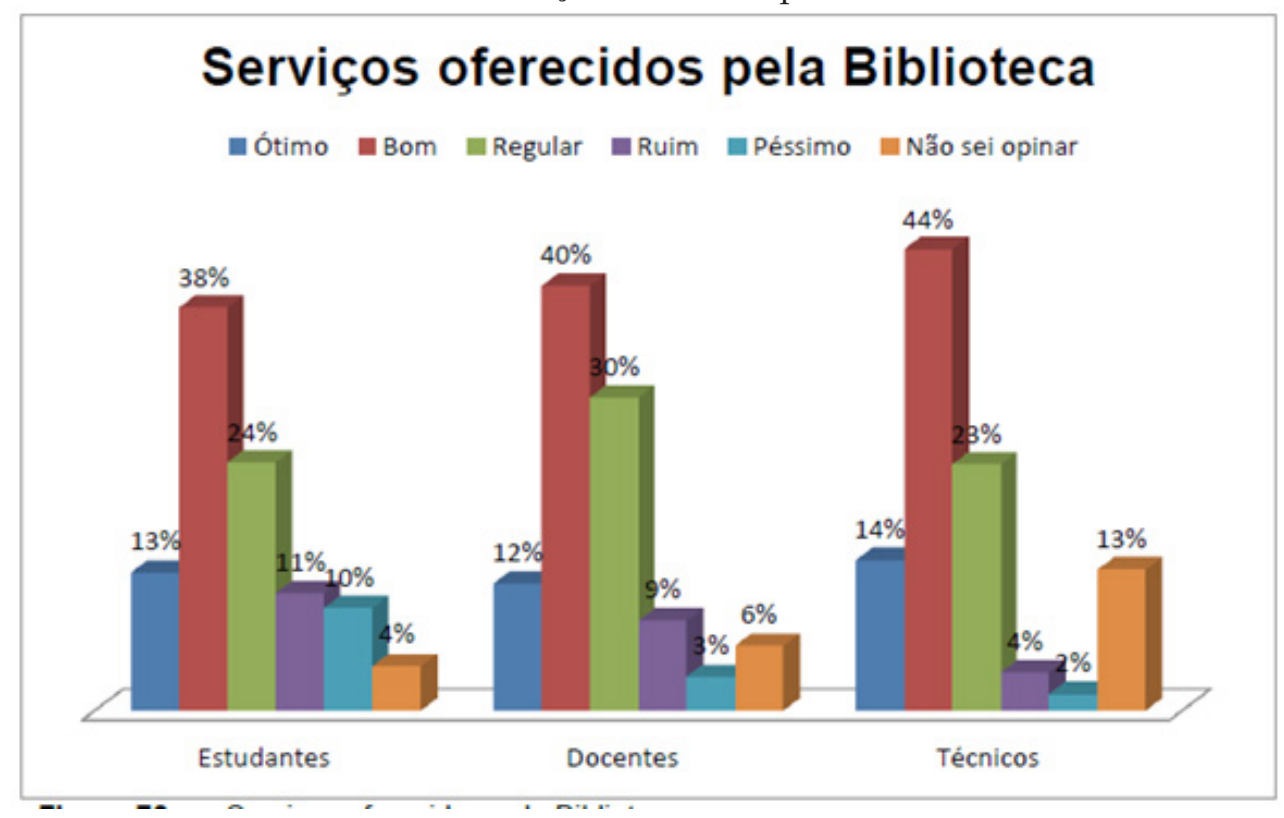

Fonte: UnB (2015, p. 175) 
Os serviços da biblioteca mudaram com o avanço da tecnologia e agora apresentam outros novos serviços tecnológicos como as Cunha (2010, p. 13), afirmando que:

\begin{abstract}
A biblioteca universitária existe porque presta serviços de atendimento no campus, de forma presencial ou virtual. O atendimento presencial tenderá a decrescer à medida que os usuários passem a utilizar, de forma intensa e variada, as inúmeras ferramentas disponíveis na chamada Web 2.0. A biblioteca não ficou parada frente a esse avanço e, nos últimos anos, essas ferramentas também passaram a ser usadas em nosso contexto. A nova biblioteca 2.0 é centrada e dirigida para o usuário com aplicações de interação, colaboração e tecnologias multimídias baseadas na internet.
\end{abstract}

A BCE oferece inúmeros produtos e serviços digitais. Todos estão listados no seu site:[http://www.bce.unb.br/servicosoferecidos/]: Biblioteca Digital de Teses e Dissertações (BDTD); Biblioteca Digital e Sonora (BDS); Repositório; Biblioteca Digital de Monografias de Graduação e Especialização
(BDM); Diretório de Periódicos Acadêmicos; LE UnB - Livros eletrônicos da UnB, biblioteca digital destinada à publicação de livros eletrônicos produzidos na UnB; Repositório de Objetos Digitais de Aprendizagem (RODA), Tradutor online integrado ao site da BCE; Catálogo público de acesso em linha (OPAC) e bases de dados.

Se os seus usuários alvos não satisfazem as suas necessidades de informação, como se pode observar no gráfico 3, é que foram inseridas as seguintes questões: A BCE tem um plano de marketing? A BCE conhece como seus não-usuários satisfazem suas necessidades de informação? A coleção da BCE está atualizada? A infraestrutura da BCE é adequada? A BCE faz estudos de usuários?

$\mathrm{Na}$ questão referida ao acervo da biblioteca, os dados mostram: $24 \%$ dos estudantes e $29 \%$ dos docentes julgaram regular, seguidos de $33 \%$ dos estudantes e $35 \%$ dos docentes julgaram bons. As coleções da BCE/UnB não satisfazem as necessidades de informação de seus usuários como se observa no gráfico 3; só $14 \%$ de estudantes e $8 \%$ de docentes avaliaram as coleções como ótimas.

Gráfico 3 - Acervo da Biblioteca

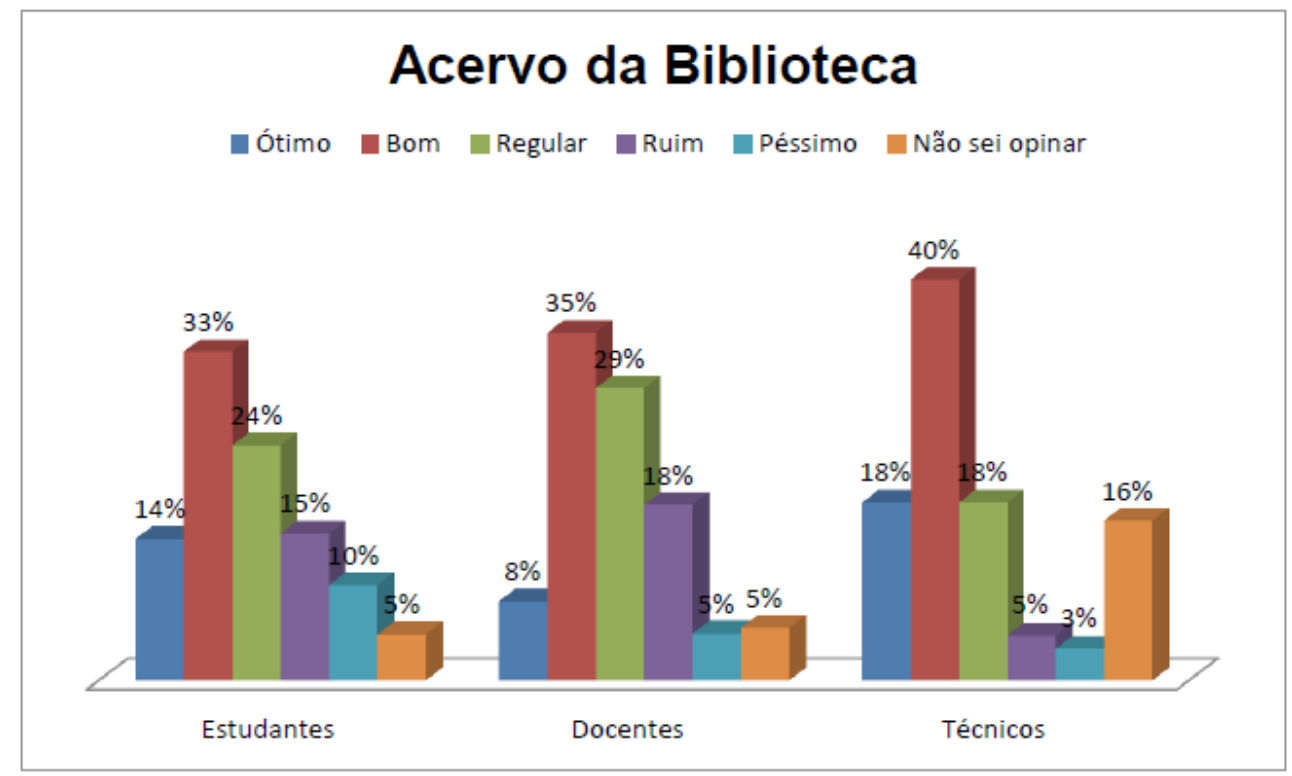

Fonte: UnB (2015, p.177) 
No outro componente citado constantemente no relatório da auto avaliação (UnB, 2015), no item Apoio Institucional à Disciplina - $1^{\circ}$ semestre de 2014 a CPA / UnB assinala que o acesso à bibliografia das disciplinas em bibliotecas da UnB obteve as pontuações mais baixas, comentando que:

Este bloco da avaliação discente foi o que obteve as médias mais baixas, se comparado ao restante da avaliação. Nenhum dos cinco itens avaliados atingiu média igual ou superior a quatro, o que mostra uma fragilidade institucional que deve ser tratada com atenção nas futuras ações de melhoria. $\bigcirc$ item "Qualidade das instalações destinadas às aulas teóricas" foi o que obteve o maior desempenho, com média de 3,69 na avaliação; já o aspecto mais mal avaliado foi o "Acesso à bibliografia das disciplinas em bibliotecas da UnB" (UnB, 2015, p. 5I).

Gráfico 4 - Acesso à bibliografia das disciplinas em bibliotecas da UnB. UnB 1/2014

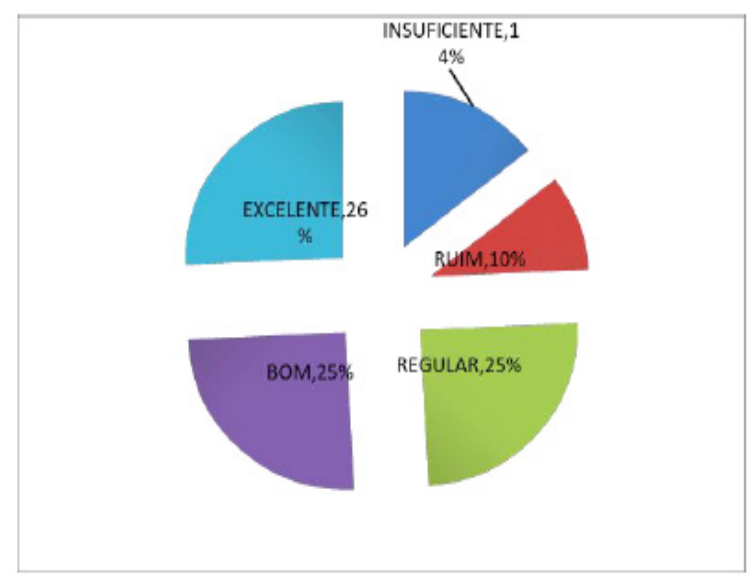

Fonte: UnB (2015, p. 51).

Os dados constantes do gráfico 4 mostram que $\mathrm{o}$ acesso às bibliografias das disciplinas na $\mathrm{BCE} / \mathrm{UnB}$ não é suficiente; $25 \%$ dos alunos afirmaram que era regular e $25 \%$, como bom. Estes dados podem mostrar que a BCE/ UnB deveria estar em contato direto com as faculdades e institutos a fim de comprar material bibliográfico com antecedência. Nesse indicador tampouco a BCE/UnB satisfaz as necessidades de informação dos alunos e docentes.

\section{CONSIDERAÇÕES FINAIS}

O presente trabalho buscou dar resposta à seguinte questão: "A Biblioteca Central da Universidade de Brasília (BCE/UnB) atende a todos os indicadores do Sistema Nacional de Avaliação da Educação Superior (SINAES) para o bom atendimento das necessidades de informação de seus usuários?

Pode-se observar que a BCE/UnB não cumpre satisfatoriamente os indicadores do SINAES relacionados à biblioteca universitária como mostra os resultados do último relatório de avaliação institucional da UnB. Esses indicadores ainda são pouco utilizados no contexto bibliotecário brasileiro e podem servir de insumos para complementar os estudos de usuários tradicionalmente realizados no âmbito da BU. É claro que esses indicadores ainda precisam de uma evolução, contemplando outros aspectos da biblioteca.

Os resultados mostraram, baseados na análise documentária, que no item infraestrutu$\mathrm{ra}$, serviços e coleções da BCE/UnB, os usuários a avaliam como regular, não contribuiriam mais fortemente na promoção da pesquisa, ensino e extensão. No item infraestrutura poderia ter mudanças imediatas no referente às salas de estudo. No item serviço é urgente a promoção e difusão a realização de um plano de marketing que possa contribuir para a identificação dos canais de comunicação mais adequados para difundir os serviços e benefícios da BU. A utilização do marketing é uma maneira de mostrar a importância da biblioteca e fazê-la visível ante os olhos da comunidade acadêmica. A aquisição de novas coleções deveria ser coordenada com as secretarias acadêmicas.

Almeida (2000, p. 74) mostrou a importância dos estudos de usuários para a avaliação dos serviços desenvolvidos pela BU. Para a autora [...] o conhecimento do usuário é indispensável, tanto para o planejamento de novos serviços de informação, como também para o aprimoramento dos serviços existentes. Em síntese, toda organização da informação tem como objetivo facilitar a recuperação e o uso oportuno da informação nos diversos contextos, para o qual as bibliotecas oferecem uma variedade de serviços os quais, certamente, geram custos inerentes de operação. $O$ uso desses serviços irá trazer respostas na oferta de informação da biblioteca, de modo a facilitar o atendimento aos usuários e trazer beneficios à sua imagem institucional, no contexto universitario. 
Artigo recebido em 22/10/2016 e aceito para publicação em 3/0 I/20I7

\title{
UNIVERSITY LIBRARY AND SINAES INDICATORS: case study of the University of Brasília
}

\begin{abstract}
This paper seeks to answer the question: Does the Central Library of the University of Brasilia (BCE/ UNB) complies with all indicators of the National Higher Education Evaluation System (SINAES) for the proper care of the information needs of its users? To provide answer to this question, it was adopted the methodology of documentary analysis, documents of the University of Brasilia and publications carried out by the committee for assessment (CPA) for the period 2014, to address the dimensions of SINAES evaluation instruments, such as physical facilities; facilities for the collection and operation; computerization. It seems that if these dimensions do not meet their goals, the target audience of the BCE/UNB will no longer be library user and will become non-user, because of the failure to meet their information needs in that library. The results of the indicators show that the BCE/UNB is not contributing in the teaching process, extension students of UNB.
\end{abstract}

Keywords: Library evaluation. National Higher Education Evaluation System. University library. University of Brasília.

\section{REFERÊNCIAS}

ALMEIDA, M. C. B. de. Planejamento de bibliotecas e serviços de informação. Brasília: Briquet de Lemos/Livros, 2000. 112 p.

AMARAL, S. A. do (Coord.). Marketing na ciência da informação. Brasília: Editora Universidade de Brasília, 2007. 229 p.

BRASIL. Avaliação do SINAES para bibliotecas universitárias: uma análise da metodologia da avaliação. In: SEMINÁRIO NACIONAL DE BIBLIOTECAS UNIVERSITÁRIAS SNBU, 17., Gramado, 2012. Anais... Disponível em: <http:/ / www.snbu2012.com.br/anais/pdf/4RAC.pdf $>$. Acesso em: 27 dez. 2015.

BRASIL. Lei $n^{\circ} .10 .861$, de 14 de abril de 2004 . Institui o Sistema Nacional de Avaliação da Educação Superior - SINAES. Diário Oficial [ da] República Federativa do Brasil, Brasília, DF, 15 abr. 2004a. Seção 1.

BRASIL. MINISTÉRIO DA EDUCAÇÃO E DO DESPORTO. Secretaria de Educação Superior. Programa de Avaliação Institucional das Universidades Brasileiras. Brasília, DF, 1994.
BRASIL. MINISTÉRIO DA EDUCAÇÃO. COMISSÃO NACIONAL DE AVALIAÇÃO DA EDUCAÇÃO SUPERIOR (CONAES). Orientações gerais para roteiro da autoavaliação das instituições. Brasília, DF: INEP, 2004b. Disponível em: <http://www.inep.gov. $\mathrm{br} /$ download/superior/sinaes/orientacoes_ sinaes.pdf>. Acesso em: 15 jul. 2016.

BRASIL. MINISTÉRIO DA EDUCAÇÃO. COMISSÃO NACIONAL DE AVALIAÇÃO DA EDUCAÇÃO SUPERIOR (CONAES). Instrumento de avaliação institucional externa subsidia os atos de credenciamento, recredenciamento e transformação da organização acadêmica (presencial). Brasília: MEC, 2014. Disponível em: <http://download. inep.gov.br/educacao_superior/avaliacao_ institucional/instrumentos/2014/instrumento_ institucional.pdf>. Acesso em: 10 jan. 2016.

COSTA, J. dos A. F. Design emocional e expressão de emoções em agentes tutores. 2009. 103 f. Dissertação (Mestrado em Comunicação Multimédia) - Departamento de Comunicação e Arte, Universidade de Aveiro, Aveiro, Portugal, 2009. Disponível em: <https://ria.ua.pt/ handle/10773/1175 >. Acesso em: 18 jun. 2016 
CUNHA, M. B. da. A Biblioteca universitária na encruzilhada. DataGramaZero: Revista de Ciencia da Informação, v. 11, n. 6, dez, 2010. Disponível em: <http://www.dgz.org.br/ dez10/F_I_onum.htm>. Acesso em: 15 nov. 2015.

CUNHA, M. B. da; AMARAL, S. A.; DANTAS, E. B. Manual de estudo de usuários da informação. São Paulo: Atlas, 2015. 448p.

DIÓGENES, F. C. B. Os novos papéis da biblioteca universitária brasileira. 2012. $444 \mathrm{f}$. Tese (Doutorado) - Universidade de Brasília, Faculdade de Ciência da Informação, Programa de Pós-Graduação em Ciência da Informação, 2012.

DUMONT, L. M. M. O não-usuário de serviços de informação, este ilustre desconhecido. In: Congresso Brasileiro de Biblioteconomia e Documentação, 17, 1994, Belo Horizonte. Anais... Belo Horizonte: Associação dos Bibliotecários de Minas Gerais, 1994, p. 697-718

FUNDAÇÃO UNIVERSIDADE DE BRASÍLIA (FUB). Estatuto e regimento geral. Disponível em: <http://www.unb.br/unb/transparencia/ downloads/regimento_estatuto_unb.pdf $>$. Acesso em: 15 de dez. 2015.

HOLANDA, N. História da avaliação. In: Avaliação de políticas públicas: conceitos básicos sobre avaliação "ex post". Rio de Janeiro: ABC, 2006. p.133-160.

\section{INSTITUTO NACIONAL DE ESTUDOS E PESQUISAS EDUCACIONAIS ANÍSIO TEIXEIRA. Resumo técnico do Exame Nacional de Cursos. Brasília, DF, 2003.}

\section{INSTITUTO NACIONAL DE ESTUDOS E PESQUISAS EDUCACIONAIS ANÍSIO TEIXEIRA. Instrumento de Avaliação Institucional Externa: instrumento. Brasília, 2010. Disponível em: <http://download.inep. gov.br/download/superior/institucional/2010/ instrumento_avaliacao_institucional_externa_ recredenciamento.pdf > Acesso em: 8 jan. 2016.}

\section{INSTITUTO NACIONAL DE ESTUDOS} E PESQUISAS EDUCACIONAIS ANÍSIO TEIXEIRA. Instrumento de Avaliação de Cursos de Graduação presencial e a distância. Brasília, DF: MEC, 2015. Disponível em: <http:/ / download.inep.gov.br/educacao_superior/ avaliacao_institucional/instrumentos/2014/ instrumento_institucional.pdf $>$. Acesso em: 5 jan. 2016.

INSTITUTO NACIONAL DE ESTUDOS E PESQUISAS EDUCACIONAIS ANÍSIO TEIXEIRA. SINAES - Sistema Nacional de Avaliação da Educação Superior: da concepção à regulamentação. Brasília, DF: MEC, 2004. Disponível em: <http://www.usjt.br/avaliacao_ inst/arquivos/sinaes.pdf>. Acesso em: $11 \mathrm{dez}$. 2015

KREMER, J. M. Considerações sobre estudos de usuários em bibliotecas universitárias. Revista da Escola de Biblioteconomia da UFMG, v. 13, n. 2, p. 234-259, 1984.

ROCHA, S. F. da; KAFURE, I. O fator emocional na interação entre o usuário e a Revista Ibero-Americana de Ciência da Informação - RICI. Revista Ibero-Americana de Ciência da Informação, Brasília, v. 6, n. 2, mar. 2014. Disponível em: <http://periodicos.unb.br/ index.php/RICI/ article/view / 8973/7661>. Acesso em: 20 mar. 2016.

SRIDHAR, M. S. Non-users and non-use of libraries. Library Science with a slant to Documentation and Information Studies, v. 31, n. 3, p. 115-128, 1994.

SILVA, A. de O. Praga ou apenas usuários deslocados? Uma visão acerca dos usuários concurseiros em bibliotecas públicas de Goiânia. 2013. 64f. Trabalho de Conclusão de Curso (Graduação em Biblioteconomia) Universidade Federal de Goiás, 2013

SOUSA, J. V. de. Educação superior no Distrito Federal: consensos, conflitos e transformações na configuração de um campo. Brasília: Líber Livro, 2013.

VIEIRA, A. da S. Visão estratégica da Biblioteca Central da UnB. Brasília, 1994. 82 f.

UNIVERSIDADE DE BRASÍLIA. Biblioteca Central. Sobre a BCE: Missão. Brasília, 2016. Disponível em: <http://www.bce.unb.br/sobrea-bce/ $\geq$ Acesso em: 12 abril de 2016. 
UNIVERSIDADE DE BRASÍLIA. Comissão Própria de Avaliação (CPA/UnB). Brasilia, 2015. Disponível em: <http://www.cpa.unb.br/> Acesso em: 10 de abril de 2016.

UNIVERSIDADE DE BRASÍLIA. Estatuto e regimento geral da Universidade de Brasília. Brasília: 2011. Disponível em: <http://www.unb. br/unb/transparencia/downloads/regimento_ estatuto_unb.pdf> Acesso em: 10 abril de 2016.

UNIVERSIDADE DE BRASÍLIA. Relatório de Autoavaliação Institucional 2014. Brasília, 2015. Disponível em: <http://www.cpa.unb. br/images/cpa/autoavaliacao/relatorio_ autoavaliacao_2014.pdf>. Acesso em: 12 jan. 2016. 